\title{
Impact of mammography screening on the treatment of women diagnosed with breast cancer
}

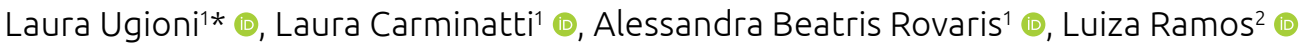

\section{ABSTRACT}

Objective: To evaluate the influence of mammographic screening on the treatment of women with previous diagnosis of breast cancer. Method: Cross-sectional, descriptive, observational study, with primary and secondary data collection and quantitative approach. It was performed in a high complexity hospital in the South region of Santa Catarina, Brazil, where patients with previous history of breast cancer were evaluated during the period from 2012 to 2017, and who were undergoing oncological follow-up at the same hospital. The variables were expressed as frequency and percentage. Inferential statistical analyses were performed with a significance level of alpha $=0.05$ and, therefore, $95 \%$ confidence interval. Therefore, the confidence interval was $95 \%$. Associations between variables were investigated using the Pearson's $\chi^{2}$ and the likelihood ratio tests. Results: Among the 99 analyzed patients, $58.6 \%$ annually performed the examination and $49.5 \%$ had elapsed less than 12 months between the last performed mammogram and the diagnosis. There was a higher frequency of stage I disease, corroborating the results that $74.7 \%$ of patients underwent breastconserving surgeries and $68.7 \%$ underwent sentinel lymph node biopsy, rather than extensive surgeries. Regarding the treatment of choice, patients with annual or biennial mammographic frequency had similar surgical and chemotherapeutic outcomes in relation to patients who had a mammogram without defined frequency or who had never undergone it. Conclusion: Patients who underwent mammography on an annual frequency and those whose time between the last mammogram and the diagnosis of cancer was less than 12 months had tumors of lesser extent at diagnosis; however, it did not influence the type of treatment chosen.

KEYWORDS: mammography; breast neoplasms; mass screening; prognosis; combined modality therapy.

\section{INTRODUCTION}

Breast cancer is the leading cause of cancer-related deaths in women worldwide. The highest mortality rate from this type of disease is verified in low- and middle-income developing countries, where about $70 \%$ of these deaths take place ${ }^{1}$. It is the most common cancer in women in Brazil and worldwide, when disregarding the prevalence of nonmelanoma skin tumors ${ }^{2}$, and the invasive ductal carcinoma is the most common histological type, with a prevalence of $80 \%$ to $90 \%$ of cases ${ }^{3}$. The incidence of breast cancer in women varies more than ten times throughout continents,and mortality varies up to four times.

Breast cancer is a very heterogeneous disease due to the plasticity of its cells. Hence, the stratification of tumors is paramount to achieve better clinical results ${ }^{4}$. In recent years, an exponential progress has been made in the molecular analysis of breast tumors, with profound implications for understanding the biology of cancer and, consequently, for its classification, allowing greater individualization and optimization of treatment.

Biomarkers of expression of estrogen receptor (ER), progesterone receptor (PR), and expression or amplification of the human epidermal growth factor receptor 2 (HER2) are part of the diagnosis of the tumor aiming at refining the classification, predicting the prognosis and, finally, individualizing the treatment of breast cancer according to the disease subtype ${ }^{5}$.

Screening for breast cancer often allows for diagnosis at earlier stages of the disease, even without lymph node involvement, and is manifested by the presence of smaller tumors. Consequently, there is a decrease in the need for extensive medical interventions and surgical approaches. Therefore, when making a decision regarding the use of mammography, one should not only take

${ }^{1}$ Universidade do Extremo Sul Catarinense - Criciúma (SC), Brazil. ${ }^{2}$ Hospital São José - Criciúma (SC), Brazil.

*Corresponding author: lauraugioni@hotmail.com

Conflict of interests: nothing to declare.

Received on: 03/13/2020. Accepted on: 08/31/2020. 
into account the survival advantage, but also the advantage of avoiding highly aggressive treatments ${ }^{6}$. That is why mammography screening is believed to save lives and has been the main pillar of screening for breast cancer?

There are many factors that must be considered when discussing the effectiveness of screening programs, assessing the positive aspects and not neglecting the negative ones as for the conduct in decision-making. Potential damage from screening includes anxiety, the cost of the test, and the morbidity associated with biopsies diagnosed as false-positive ${ }^{8}$.

The combined action of mammography exam and the regular use of adjuvant therapies in the early detection and treatment of breast cancer has been decisive in considerably reducing mortality from this disease in recent decades. The prognosis in each woman is closely related to the tumor's genetic profile and, although findings on imaging studies may be nonspecific, there are cases in which characteristic traits that guide a specific molecular subtype can be identified ${ }^{9}$.

Because of multiple prognostic factors that must be taken into account when considering eligibility for treatment, such as age, reproductive status (before or after menopause), type, and severity of cancer, it is not possible to establish clear standards of conduct regarding the disease, as there are many different clinical situations ${ }^{10}$. The treatment of breast cancer is complex and requires a multidisciplinary approach, which may include surgery, radiotherapy, and systemic therapy (chemotherapy, hormonal, or biological therapy) ${ }^{11}$.

As previously described, mammography is the most important method of screening for breast cancer, representing a fundamental tool for the assessment and clarification of the various abnormalities found in the breasts. Considering its importance, the objective of the present study was to evaluate the influence of mammographic screening on the treatment of women with a previous diagnosis of breast cancer and who were undergoing outpatient follow-up care.

\section{METHODS}

\section{Ethical considerations}

The data of the present study were only collected after approval by the Human Research Ethics Committee of Universidade do Extremo Sul Catarinense, under opinion No. 3.084.495, and by the Research Ethics Committee of the hospital where the study was carried out, under opinion No. 3,202,104.

\section{Study design}

This is a cross-sectional, descriptive, observational study, with primary and secondary data collection and quantitative approach. The analysis was carried out in a public hospital of regional reference located in the city of Criciúma, in the South of the state of Santa Catarina, Brazil. The evaluated patients were women, with a previous diagnosis of breast cancer during the period from 2012 to 2017, and who were undergoing outpatient followup care at the same hospital.

106 patients were evaluated. Of these, seven were excluded due to incomplete information in the medical records or because they had not yet completed the treatment. Therefore, a total of 99 patients were included in the study in order to assess the relationship between the date of the last mammography prior to diagnosis and the frequency with which the examination was performed, and TNM staging (extension of the primary tumor, lymph nodes affected by metastasis, and distant metastasis) at the time of diagnosis and the therapy adopted for each tumor stage.

For the collection of secondary data, the following information was extracted from the medical records: age of the patient (4049 years, $50-59$ years, $60-69$ years, $\geq 70$ years); skin color (white, black, or other); menopausal status (pre- or postmenopausal); tumor characteristics, such as TNM staging and immunohistochemistry; type of breast surgery (breast-conserving or mastectomy); axillary surgery (sentinel lymph node, axillary dissection, or none); and chemotherapy (adjuvant, neoadjuvant, or none).

Primary data were collected through a questionnaire applied and developed by the researchers. It contained two items:

- time elapsed between the last mammography before the diagnosis of breast cancer and the diagnosis (more than 24 months, between 12-24 months, or less than 12 months);

- frequency of mammography screening (annually, biannually, undefined frequency, or had never performed).

\section{Statistical analysis}

The collected data were organized and analyzed using the IBM Statistical Package for the Social Sciences (SPSS) software, version 21.0. Variables were expressed as frequency and percentage. Inferential statistical analyses were performed with a significance level of alpha $=0.05$. Therefore, the confidence interval was $95 \%$.

Associations between the variables were investigated by applying the Pearson's $\chi^{2}$ and likelihood ratio tests, with subsequent analysis of residuals in cases that showed statistical significance.

\section{RESULTS}

The clinical and epidemiological profile of the 99 patients analyzed in the present study is described in Table 1, which shows characteristics, such as the age, skin color, and menopausal status of each patient, in addition to the TNM staging of the tumors and immunohistochemical characteristics such as expression of estrogen receptor (ER), progesterone receptor (PR), expression or amplification of human epidermal growth factor receptor 2 (HER2), and cell proliferation marker (Ki67). 
When analyzing the therapy adopted for each patient, regarding the type of breast surgery, 74.7\% (74/99) of them underwent breast-conserving surgery and 25.3\% (25/99), mastectomy. Concerning the axillary approach, 68.7\% (68/99) underwent sentinel lymph node biopsy; 27.3\% (27/99) required lymph node dissection; and 4\% (4/99) did not undergo any axillary surgical approach. As for chemotherapy, 34.3\% (34/99) of them underwent adjuvant chemotherapy; 33.3\% (33/99), neoadjuvant chemotherapy; and $32.3 \%$ (32/99), none.

The participants of the present study were also asked about the time elapsed between the last mammography before the diagnosis and the diagnosis of cancer, and 33.3\% (33/99) stated that more than 24 months had passed; 17.2\% (17/99), between 12 and 24 months; and 49.5\% (49/99), less than 12 months. They were also asked about the frequency of mammography screening: $58.6 \%$ (58/99) answered that they annually performed it; $3 \%$ (3/99), biannually; $20.2 \%$ (20/99) reported undefined frequency; and $18.2 \%$ (18/99) had never done it.

The correlation between the date of the last mammography prior to the diagnosis and the frequency with which the examination was performed with the TNM staging at diagnosis is demonstrated in Tables 2 and 3.

Table 2 shows the relationship between the time elapsed between the last mammography performed by the patient and the diagnosis of breast cancer with TNM staging. Based on the extension of the primary tumor, it was observed that the performance of the last mammography in less than 12 months until the diagnosis was correlated with tumors of smaller extension $(\mathrm{p}=0.026)$.

When analyzing lymph nodes affected by metastasis and the presence or absence of distant metastases, it was also found that the shorter the time elapsed between the last mammography and the cancer diagnosis (less than 12 months), the more tumors with little or no affected lymph node and tumors without distant metastases were found. Nevertheless, none of the analyses has statistical significance ( $\mathrm{p}>0.05)$.

Table 3 shows the correlation between TNM staging and the frequency of mammography screening. When analyzing the extension of the primary tumor, it was verified that mammography with annual frequency is associated with tumors of lesser extent $(\mathrm{p}=0.041)$. When associating the screening frequency and lymph node involvement with the presence of distant metastases, there was no statistical significance ( $p>0.05$ ).

Correlation between the frequency of mammography screening and the therapy adopted for each patient is demonstrated in Table 4. Study participants were asked about the frequency for performing the examination, and this datum was crossed with the treatments and interventions that each patient underwent such as breast surgery, axillary surgery, and the adopted chemotherapy intervention. Such analyses, described in Table 4, had no statistical significance.
The time elapsed between the last mammography screening and the diagnosis of breast cancer was also correlated with the chosen therapeutic approach. Among the 49 patients who had undergone the examination less than 12 months ago, $77.6 \%$ (38/49) underwent breast-conserving surgery; $22.4 \%$ (11/49), mastectomy; $63.3 \%$ (31/49), sentinel lymph node biopsy; $28.6 \%$ (14/49), axillary dissection; and 8.2\% (4/49), no axillary approach.

Among the 17 patients whose elapsed time from the last mammography was between 12 and 24 months, 70.6\% (12/17) underwent breast-conserving surgery and $29.4 \%$ (5/17) required

Table 1. Clinical-epidemiological profile of the sample.

\begin{tabular}{|c|c|}
\hline & n (\%) \\
\hline & $\mathrm{n}=99$ \\
\hline \multicolumn{2}{|l|}{ Age (years) } \\
\hline $40-49$ & $38(38.4)$ \\
\hline $50-59$ & $26(26.3)$ \\
\hline $60-69$ & $21(21.2)$ \\
\hline$\geq 70$ & $14(14.1)$ \\
\hline \multicolumn{2}{|l|}{ Skin color } \\
\hline White & $94(94.9)$ \\
\hline Black & $4(4.0)$ \\
\hline Other & $1(1.0)$ \\
\hline \multicolumn{2}{|l|}{ Menopausal status } \\
\hline Premenopausal & $28(28.3)$ \\
\hline Postmenopausal & $71(71.7)$ \\
\hline \multicolumn{2}{|l|}{ Primary tumor extension (T) } \\
\hline T1 & $59(59.6)$ \\
\hline $\mathrm{T} 2$ & $28(28.3)$ \\
\hline T3 & $8(8.1)$ \\
\hline T4 & $4(4.0)$ \\
\hline \multicolumn{2}{|c|}{ Lymph nodes affected by metastasis (N) } \\
\hline No & $65(65.7)$ \\
\hline N1 & $25(25.3)$ \\
\hline N2 & $6(6.1)$ \\
\hline N3 & $3(3.0)$ \\
\hline \multicolumn{2}{|l|}{ Distant metastasis (M) } \\
\hline M0 & $96(97.0)$ \\
\hline M1 & $3(3.0)$ \\
\hline Positive estrogen receptor & $83(83.8)$ \\
\hline Positive progesterone receptor & $73(73.7)$ \\
\hline Positive HER2 & $11(11.1)$ \\
\hline \multicolumn{2}{|l|}{ Ki67 } \\
\hline Lower than $14 \%$ & $64(64.6)$ \\
\hline Higher than or equal to $14 \%$ & $35(35.4)$ \\
\hline
\end{tabular}

HER2: human epidermal growth factor receptor 2. 
mastectomy. Regarding axillary surgery, 64.7\% (11/17) underwent sentinel lymph node biopsy, and 35.3\% (6/17) underwent axillary dissection.

When analyzing the 33 patients whose elapsed time of the last examination and the diagnosis was over 24 months, it was noted that $72.7 \%$ (24/33) underwent breast-conserving surgery; $27.3 \%$, mastectomy; $78.8 \%$ (26/33), sentinel lymph node biopsy; and $21.2 \%$ (7/33), axillary dissection. However, no statistical significance was found in such analyses.
In Table 5, the relationship between the immunohistochemical profile of the tumors (with regard to the expression of estrogen receptor, progesterone receptor, expression or amplification of human epidermal growth factor receptor 2 - HER2 - , and Ki67) and chemotherapy was analyzed, whether the chemotherapy was adjuvant, neoadjuvant, or not performed. When observing this table, it is noteworthy that most patients who underwent chemotherapy had positive hormone receptors, especially when the progesterone receptor was verified, with statistical significance

Table 2. Correlation between tumor staging and time elapsed between the last mammography and the diagnosis of breast cancer.

\begin{tabular}{|c|c|c|c|c|}
\hline & \multicolumn{3}{|c|}{ Time between last mammography and diagnosis n (\%) } & \multirow{2}{*}{ p-value* } \\
\hline & More than 24 months & Between 12 and 24 months & Less than 12 months & \\
\hline Primary tumor extension ( $T$ ) & $\mathrm{n}=33$ & $\mathrm{n}=17$ & $\mathrm{n}=49$ & \\
\hline T1 & $17(51.5)$ & $13(76.5)$ & $29(59.2)$ & \multirow{4}{*}{0.026} \\
\hline $\mathrm{T} 2$ & $13(39.4)$ & $3(17.6)$ & $12(24.5)$ & \\
\hline T3 & $0(0.0)$ & $1(5.9)$ & $7(14.3)$ & \\
\hline $\mathrm{T} 4$ & $3(9.1)$ & $0(0.0)$ & $1(2.0)$ & \\
\hline \multicolumn{5}{|c|}{ Lymph nodes affected by metastasis ( $\mathrm{N}$ ) } \\
\hline No & $22(66.7)$ & $11(64.7)$ & $32(65.3)$ & \multirow{4}{*}{0.873} \\
\hline N1 & $9(27.3)$ & $5(29.4)$ & $11(22.4)$ & \\
\hline N2 & $1(3.0)$ & $1(5.9)$ & $4(8.2)$ & \\
\hline N3 & $1(3.0)$ & $0(0.0)$ & $2(4.0)$ & \\
\hline \multicolumn{5}{|l|}{ Distant metastasis (M) } \\
\hline MO & $32(97.0)$ & $17(100.0)$ & 47 (95.9) & \multirow{2}{*}{0.545} \\
\hline M1 & $1(3.0)$ & $0(0.0)$ & $2(4.1)$ & \\
\hline
\end{tabular}

*Value obtained after applying the likelihood ratio test.

Table 3. Correlation between tumor staging and frequency of mammography screening.

\begin{tabular}{|c|c|c|c|c|c|}
\hline & \multicolumn{4}{|c|}{ Frequency of mammography, n (\%) } & \multirow{2}{*}{ p-value* } \\
\hline & Annually & Biannually & Undefined frequency & Had never done it & \\
\hline Primary tumor extension ( $\mathrm{T}$ ) & $\mathrm{n}=58$ & $\mathrm{n}=3$ & $\mathrm{n}=20$ & $\mathrm{n}=18$ & \\
\hline $\mathrm{T} 1$ & $36(62.1)$ & $3(100.0)$ & $12(60.0)$ & $8(44.4)$ & \multirow{4}{*}{0.041} \\
\hline $\mathrm{T} 2$ & $15(25.9)$ & $0(0.0)$ & $6(30.0)$ & $7(38.9)$ & \\
\hline T3 & $7(12.1)^{b}$ & $0(0.0)$ & $1(5.0)$ & $0(0.0)$ & \\
\hline $\mathrm{T} 4$ & $0(0.0)$ & $0(0.0)$ & $1(5.0)$ & $3(16.7)$ & \\
\hline \multicolumn{6}{|c|}{ Lymph nodes affected by metastasis (N) } \\
\hline No & $37(63.8)$ & $2(66.7)$ & $14(70.0)$ & $12(66.7)$ & \multirow{4}{*}{0.591} \\
\hline N1 & $15(25.9)$ & $1(33.3)$ & $4(20.0)$ & $5(27.8)$ & \\
\hline N2 & $5(8.6)$ & $0(0.0)$ & $0(0.0)$ & $1(5.6)$ & \\
\hline N3 & $1(1.7)$ & $0(0.0)$ & $2(10.0)$ & $0(0.0)$ & \\
\hline \multicolumn{6}{|l|}{ Distant metastasis (M) } \\
\hline MO & $56(96.6)$ & $3(100.0)$ & $20(100.0)$ & $17(94.4)$ & \multirow{2}{*}{0.623} \\
\hline M1 & $2(3.4)$ & $0(0.0)$ & $0(0.0)$ & $1(5.6)$ & \\
\hline
\end{tabular}

bStatistically significant values after analysis of residuals $(p<0.05)$; *value obtained after applying the likelihood ratio test. 
( $\mathrm{p}<0.001)$, negative HER2, and a cell proliferation marker lower than or equal to $14 \%$, characterizing tumors of the luminal subtype.

Furthermore, the relationship between TNM staging and the adopted therapeutic approach was analyzed. Patients were divided between 74, who underwent breast-conserving surgery, and 25, who underwent mastectomy. When correlating the extension of the primary tumor and the type of breast surgery adopted, it was verified that, among patients who underwent conservative surgical treatment, in $67.6 \%(50 / 74)$ of the cases the tumors were T1; in $28.4 \%(21 / 74), \mathrm{T} 2$; in $2.7 \%(2 / 74)$, T3; and in $1.4 \%(1 / 74)$, T4.
Conversely, when observing patients who underwent mastectomy, in $36 \%$ (9/25) of them the tumors were T1; in 28\% (7/25), T2; in $24 \%(6 / 25)$, T3; and in $12 \%$ (3/25), T4. Thus, it was noted that the more initial the tumor staging, the more conservative breast surgery was chosen as the adopted therapy, obtaining statistical significance $(\mathrm{p}<0.001)$. The same was observed for lymph nodes affected by metastasis. It was found that, among patients who underwent conservative surgery, 77\% (57/74) had N0 tumors; $17.6 \%$ (13/74), N1 tumors; 2.7\% (2/74), N2 tumors; and 2.7\% (2/74), N3 tumors.

When analyzing the patients who underwent mastectomy, $32 \%(8 / 25)$ had N0 tumors; 48\% (12/25), N1 tumors; 16\% (4/25),

Table 4. Correlation between the frequency of mammography screening and the chosen therapeutic approach.

\begin{tabular}{|c|c|c|c|c|c|}
\hline & \multicolumn{4}{|c|}{ Frequency of mammography, n (\%) } & \multirow{3}{*}{ p-value* } \\
\hline & Annually & Biannually & Undefined frequency & Had never done it & \\
\hline & $\mathrm{n}=58$ & $n=3$ & $\mathrm{n}=20$ & $\mathrm{n}=18$ & \\
\hline \multicolumn{6}{|l|}{ Breast-conserving } \\
\hline Surgery & $42(72.4)$ & $3(100.0)$ & $17(85.0)$ & $12(66.7)$ & \multirow{2}{*}{0.291} \\
\hline Mastectomy & $16(27.6)$ & $0(0.0)$ & $3(15.0)$ & $6(33.3)$ & \\
\hline \multicolumn{6}{|l|}{ Axillary surgery } \\
\hline Sentinel lymph node & $35(60.3)$ & $2(66.7)$ & $17(85.0)$ & $14(77.8)$ & \multirow{3}{*}{0.241} \\
\hline Axillary dissection & $19(32.8)$ & $1(33.3)$ & $3(15.0)$ & $4(22.2)$ & \\
\hline No & $4(6.9)$ & $0(0.0)$ & $0(0.0)$ & $0(0.0)$ & \\
\hline \multicolumn{6}{|l|}{ Adjuvant } \\
\hline Chemotherapy & $18(31.0)$ & $2(66.7)$ & $7(35.0)$ & $7(38.9)$ & \multirow{3}{*}{0.577} \\
\hline Neoadjuvant & $21(36.2)$ & $0(0.0)$ & $5(25.0)$ & $7(38.9)$ & \\
\hline No & $19(32.8)$ & $1(33.3)$ & $8(40.0)$ & $4(22.2)$ & \\
\hline
\end{tabular}

*Value obtained after applying the likelihood ratio test.

Table 5. Relationship between immunohistochemical profile of the tumor and chemotherapy.

\begin{tabular}{|c|c|c|c|c|}
\hline & \multicolumn{3}{|c|}{ Chemotherapy n (\%) } & \multirow{2}{*}{ p-value } \\
\hline & Neoadjuvant & chemotherapy & No & \\
\hline Estrogen receptor & $n=34$ & $\mathrm{n}=33$ & $\mathrm{n}=32$ & \\
\hline Positive & $29(85.3)$ & $24(72.7)$ & $30(93.8)$ & $0.068^{*}$ \\
\hline Negative & $5(14.7)$ & $9(27.3)$ & $2(6.3)$ & \\
\hline \multicolumn{5}{|l|}{ Progesterone receptor } \\
\hline Positive & $27(79.4)$ & $16(48.5)$ & $30(93.8)$ & \multirow{2}{*}{$<0.001^{*}$} \\
\hline Negative & $7(20.6)$ & $17(51.5)^{*}$ & $2(6.3)$ & \\
\hline \multicolumn{5}{|l|}{ HER2 } \\
\hline Positive & $3(8.8)$ & $7(21.2)$ & $1(3.1)$ & \multirow{2}{*}{$0.056^{*}$} \\
\hline Negative & $31(91.2)$ & $26(78.8)$ & $31(96.9)$ & \\
\hline \multicolumn{5}{|l|}{ Ki67 } \\
\hline Lower than or equal to $14 \%$ & $23(67.6)$ & $20(60.6)$ & $21(65.6)$ & \multirow{2}{*}{$0.826^{*}$} \\
\hline Higher than 14\% & $11(32.4)$ & $13(39.4)$ & $11(34.4)$ & \\
\hline
\end{tabular}

*Values obtained after applying the Fisher's exact test; **value obtained after applying the Pearson's $\chi^{2}$ test; HER2: human epidermal growth factor receptor 2. 
N2 tumors; and 4\% (1/25), N3 tumors. That is, when having no involvement or the lesser the involvement of the tumors, the more breast-conserving surgery was adopted $(\mathrm{p}<0.001)$.

When correlating the presence or absence of distant metastases and the diagnosis with the breast surgery chosen, breast-conserving surgery was preferred in the cases of absence of metastases. However, these data are not statistically significant $(\mathrm{p}=0.156)$.

Still on the relationship between the TNM staging and the adopted therapeutic approach, when the tumor staging was associated with the type of axillary surgery, of the 68 patients who underwent sentinel lymph node biopsy, 66.2\% (45/68) were classified as T1; 23.5\% (16/68), T2; 5.9\% (4/68), T3; and $4.4 \%$ (3/68), T4.

As for lymph nodes affected by metastasis, $79.4 \%(54 / 68)$ had N0 tumors; $17.6 \%$ (12/68), N1 tumors; $1.5 \%$ (1/68), N2 tumors; and $1.5 \%(1 / 68)$, N3 tumors. Concerning distant metastases, $97.1 \%$ $(66 / 68)$ had no evidence of metastasis, being classified as M0, and $2.9 \%(2 / 68)$ were classified as M1.

Among the 27 patients who underwent axillary dissection, with regard to the extension of the primary tumor, $40.7 \%$ (11/27) were classified as T1; 40.7\% (11/27), T2; 14.8\% (4/27), T3; and 3.7\% (1/27), T4. As for the affected lymph nodes, $25.9 \%$ (7/27) of the patients had N0 tumors; $48.1 \%$ (13/27), N1 tumors; $18.5 \%$ (5/27), N2 tumors; and 7.4\% (2/27), N3 tumors.

Considering distant metastases, 96.3\% (26/27) were classified as M0, and $3.7 \%(1 / 27)$ as M1. When analyzing the four patients who did not undergo any axillary surgical approach, $75 \%$ (3/4) were classified as T1, and 25\% (1/4) as T2. Regarding the affected lymph nodes, $100 \%$ patients were classified as N0 and, in relation to distant metastases, $100 \%$ had M0 tumors. The correlation between the affected lymph nodes and the type of axillary surgery was statistically significant, with $\mathrm{p}<0.001$.

The correlation between TNM staging at the time of diagnosis and whether the patients undergone chemotherapy (adjuvant or neoadjuvant) or not was also analyzed. Among the evaluated patients, 34 underwent adjuvant chemotherapy; 33, neoadjuvant chemotherapy; and 32 did not undergo chemotherapy.

Among patients who underwent adjuvant chemotherapy, and according to the extension of the primary tumor, in $55.9 \%$ $(19 / 34)$ of the cases the tumors were T1; in $41.2 \%$ (14/34), T2; in $2.9 \%(1 / 34)$, T3; and none of them met the criteria for the T4 classification. Among these same patients and by analyzing the lymph nodes affected by metastasis, in $67.6 \%$ (23/34) of the cases the tumors were N0; in $23.5 \%$ (8/34), N1; in $2.9 \%$ (1/34), N2; and in $5.9 \%(2 / 34), \mathrm{N} 3$.

As for patients who underwent neoadjuvant chemotherapy and according to the extension of the primary tumor, $36.4 \%$ (12/33) of the cases had T1 tumors; $30.3 \%$ (10/33), T2; $21.2 \%$ (7/33), T3; and $12.1 \%(4 / 33), \mathrm{T} 4$. When lymph nodes affected by metastasis were examined in these same patients, in $39.4 \%$ (13/33) the tumors were N0; in 42.4\% (14/33), N1; in 15.2\% (5/33), N2; and in 3\% (1/33), N3.
Among patients who did not undergo chemotherapy and by analyzing the extension of the primary tumor, $87.5 \%$ (28/32) had T1 tumors; $12.5 \%$ (4/32), T2; and none of them presented $\mathrm{T} 3$ or $\mathrm{T} 4$ tumors. Likewise, when analyzing lymph nodes affected by metastasis, $90.6 \%$ (29/32) of the patients had N0 tumors, and 9.4\% (3/32) had N1 tumors. That is, none had N2 or N3 tumors. Such data crossings obtained statistical significance, with $\mathrm{p}<0.001$.

This analysis does not include the evaluation of distant metastases considering that, when present, the adopted approach involves palliative therapy, no longer with curative purposes.

\section{DISCUSSION}

The present study evaluated the influence of mammographic screening on the treatment of women with previous diagnosis of breast cancer.

Regarding the clinical-epidemiological profile of patients and by evaluating the global statistics on the prevalence of breast cancer, the incidence of this type of neoplasia progressively increases from the age of $40^{2}$, in line with what was observed in this study, in which most patients, 38.4\% (38/99), aged between 40 and 49 years and $26.3 \%$ (26/99), between 50 and 59 years. The result is similar to that found in a Brazilian study that states that, in developing countries, the incidence of breast cancer in women aged between 40 and 50 years is higher than in developed countries ${ }^{12}$.

Corroborating such information, in the present study, $71.7 \%$ (71/99) of the patients obtained the diagnosis already in the postmenopausal stage, and, of the observed population, $94.9 \%$ (94/99) were white. Similar characteristics were found in the study conducted by Miglioretti et al., who obtained a sample of 15,440 women with breast cancer, in which the majority were 50 years old or older $(85.4 \%)$, white $(78.1 \%)$, and were in the postmenopausal stage $(63.6 \%)^{13}$.

When evaluating the patients' performance of mammography, the present study showed that most of them, $58.6 \%$ (58/99), annually underwent the examination, against $20.2 \%$ (20/99) who had undefined frequency, $3 \%$ (3/99) who biannually performed it, and $18.2 \%$ (18/99) who had never done it. Similar results are reported in the study of Ribeiro et al., in which $53 \%$ of the evaluated patients had an annual screening frequency; $12.5 \%$, biannual; $23 \%$, irregular; and $8.5 \%$ had never been screened ${ }^{14}$.

The fact that both studies show that most patients underwent annual screening is extremely important, considering that mammography is the most reliable and reproducible secondary prevention method for detecting breast cancer. When performed with certified equipment, by qualified technicians, and with the interpretation of experienced radiologists, the accuracy rate of $85 \%$ to $90 \%$ can be achieved for the identification of nonpalpable preclinical tumors ${ }^{15}$. 
In this study, when assessing the time elapsed between the last mammography before the diagnosis of breast cancer and the diagnosis, it was observed that 49.5\% (49/99) of the participants had done the examination less than 12 months ago; in $17.2 \%$ (17/99) of the cases, between 12 and 24 months; and in 33.3\% (33/99), for more than 24 months. Similar data were found in the study conducted by Ahn et al., in which, among the 1,125 analyzed patients, $73 \%$ had been screened 24 months before diagnosis and $27 \%$ had been screened over 25 months ago ${ }^{6}$.

Regarding TNM staging, in the present study, there was a higher frequency of stage I breast cancer, that is, tumors of 2 centimeters or less, without lymph node involvement, and absence of metastases ${ }^{16}$. The higher frequency of tumors in early stages may justify the fact that most patients in this study underwent breast-conserving surgeries (74.7\%) and sentinel lymph node biopsy (68.7\%) rather than more aggressive therapeutic methods.

Corroborating this finding, in the study conducted by Ribeiro et al., based on database of the Núcleo de Mama de Porto Alegre, Núcleo de Mama Moinhos, and Hospital de Clínicas de Porto Alegre, among patients who were classified as stage I, 73\% underwent breast-conserving surgeries ${ }^{14}$. This can be justified by the study of Barth et al., who observed that breast cancers detected by mammography are of lesser extent, less likely to metastasize to the lymph nodes and, thus, more likely to be treated with breast-conserving surgery ${ }^{8}$.

When assessing the adopted treatment and its relationship with mammography screening, the present study showed that patients who underwent mammography biannually or more frequently had outcomes of surgical interventions and chemotherapy treatment similar to those of women who underwent mammography without defined frequency or who had never done it. This result is also evidenced by the study of Ahn et al., who demonstrated less invasive therapeutic interventions in patients who underwent mammography with a biennial frequency ${ }^{6}$, although in the present study the absolute majority of patients had undergone less invasive treatments.

The study conducted by McDonald et al. concluded that the treatment must integrate the analysis of immunohistochemical markers and gene expression with information on anatomical margins and imaging studies, in order to individualize the treatment plan and the response to treatment ${ }^{17}$. This conclusion somewhat justifies what was found in the present study, in which the therapeutic modalities, both surgical and chemotherapeutic, proved to be similar among patients. Thus, the similarity in therapeutic approaches can be explained based on the molecular subtypes verified and on the performance of neoadjuvant therapies, and not only on the fact that surgical techniques tend to be less aggressive nowadays.

That is why gene expression has become an essential finding in understanding the biology of cancer, considering that each molecular subtype has significant differences in terms of incidence, risk factors, sensitivity to treatment, and prognosis ${ }^{18}$.

In this study, among patients who had done their last mammography prior to diagnosis less than 12 months ago, 8.2\% (4/49) did not require an axillary surgical approach and 63.3\% (31/49) only underwent sentinel lymph node biopsy, thus corroborating studies whose authors state that low-grade tumors at diagnosis result in less lymph node involvement, requiring less interventions, as shown by the study of Warrier et al. ${ }^{19}$. Therefore, less extensive treatments are expected in patients undergoing screening, as endorsed by Brazilian recommendations ${ }^{20}$, considering the well-known relationship between mammography screening and less lymph node involvement at diagnosis.

Surgical and chemotherapy outcomes were similar among patients with annual or biennial frequency of mammography screening and those who underwent mammography without a defined frequency or who had never done it; this probably occurred because, nowadays, regarding surgical treatment, breast-conserving surgery is preferred to mastectomy, followed by adjuvant radiotherapy, as well as sentinel lymph node biopsy, which have been chosen as treatments rather than axillary dissection for presenting less iatrogenesis and equivalent survival rates ${ }^{18,21}$.

Furthermore, this outcome may be corroborated by the fact that most patients are younger (40-49 years of age), an age group in which there is disagreement in the Brazilian Ministry of Health concerning mammography screening, as the department is against screening for women under 50 years of age ${ }^{20}$, and also because most tumors present in the current study are of the luminal subtype, i.e., less aggressive and of slower growth ${ }^{22}$. This evidences that multiple prognostic factors must be taken into account when considering the ideal therapeutic modality that the patient will undergo, especially when it comes to molecular analysis and biological behavior of the tumor.

In a recent study conducted by Duffy et al., aiming at estimating the influence of annual mammography screening before the age of 50 , the authors observed that the reduction of the age limit for undergoing the screening, from 50 to 40 years, could potentially decrease mortality from such cancer ${ }^{23}$. This fact justifies the findings of the present study, in which the absolute majority of analyzed women underwent mammography on an annual basis and were younger, i.e., aged between 40 and 49 years, an age group to which screening is not recommended according to national guidelines. However, such patients had tumors of lesser extent at diagnosis, with more conservative therapeutic modalities and higher survival rates.

As limitations of the present study, there is lack of information in the patients' medical records, causing the sample to be reduced. All participating patients underwent treatment subsidized by the Brazilian Unified Health System, and there may be financial limitations to such treatment. 


\section{CONCLUSION}

It was observed that, in patients who annually underwent mammography and those whose elapsed time between the last mammography and the diagnosis of cancer was less than 12 months, at the time of diagnosis the tumors were of lesser extent, without, however, influencing the type of therapy adopted for treatment, considering that the absolute majority of evaluated patients were treated with less invasive therapeutic methods.

Therapeutic modalities were similar between the groups, even if differently performing the screening or not performing it, and this may be due to the fact that the absolute majority of patients had tumors of the luminal subtype, i.e., less aggressive, of slower growth, and that had positive hormone receptors, making it possible, in many cases, to undergo neoadjuvant chemotherapy.

This strategy has been increasingly frequent in the management of breast cancer, becoming an alternative even for tumors of greater extent, primarily treated by systemic therapy and, later, with less extensive surgical approaches. Another strategy is the acknowledged tendency to prefer breast-conserving surgeries and sentinel lymph node biopsy to more extensive surgeries, considering that these procedures present less iatrogenesis and equivalent survival rates.

New studies that highlight, in the long term, the impact of mammography on mortality, in addition to the morbidity related to the most diverse therapeutic methods available, considering the heterogeneity of this type of cancer, would be relevant to clinical updates.

\section{AUTHORS' CONTRIBUITIONS}

L.U.: Conceptualization, data collection and analysis, methodology, project management, writing, supervision, validation, review and editing.

L.C.: Conceptualization, data collection and analysis, methodology, project management, writing, supervision, validation, review and editing.

A.R.: Conceptualization, project management, supervision and review.

\section{REFERENCES}

1. Lukong KE, Ogunbolude Y, Kamdem JP. Breast cancer in Africa: prevalence, treatment options, herbal medicines, and socioeconomic determinants. Breast Cancer Res Treat. 2017;166(2):351-65. Breast cancer in Africa: prevalence, treatment options, herbal medicines, and socioeconomic determinants. Breast Cancer Res Treat.

2. Instituto Nacional de Câncer Jose Alencar Gomes da Silva. Programa Controle de Câncer de Mama [Internet]. Brazil: INCA; 2018 [accessed on Oct. 27, 2018]. Available from: https:/www.inca.gov.br/tipos-de-cancer/cancer-de-mama/ profissional-de-saude

3. Instituto Nacional de Câncer Jose Alencar Gomes da Silva. Estimativa 2018: Incidência de Câncer no Brasil [Internet]. Rio de Janeiro: Ministério da Saúde; 2018 [accessed on Oct. 16, 2018]. Available from: http://www.epi.uff.br/wp-content/ uploads/2013/08/estimativa-incidencia-de-cancer-nobrasil-2018.pdf

4. Yeo SK, Guan JL. Breast cancer: multiple subtypes within a tumor? Trends Cancer. 2017; 3(11):753-60. https://doi. org/10.1016/j.trecan.2017.09.001

5. Vuong D, Simpson PT, Green B, Cummings MC, Lakhani SR. Molecular classification of breast cancer. Virchows Arch. 2014;465(1):1-14. https://doi.org/10.1007/s00428-014-1593-7

6. Ahn S, Wooster M, Valente C, Moshier E, Meng R, Pisapati $\mathrm{K}$, et al. Impact of screening mammography on treatment in women diagnosed with breast cancer. Ann Surg Oncol. 2018;25(10):2979-86. https://doi.org/10.1245/s10434-0186646-8

7. Lebron-Zapata L, Jochelson MS. Overview of Breast Cancer Screening and Diagnosis. PET Clin. 2018;13(3):301-23. https:// doi.org/10.1016/j.cpet.2018.02.001
8. BarthJr. RJ, Gibson GR, CarneyPA, MottLA, Becher RD, Poplack SP. Detection of breast cancer on screening mammography allows patients to be treated with less-toxic therapy. AJR Am J Roentgenol. 2005;184(1):324-9. https://doi.org/10.2214/ ajr.184.1.01840324

9. Merino Bonilla JA, Torres Tabanera M, Ros Mendoza LH. El cáncer de mama en el siglo XXI: de la detección precoz a los nuevos tratamientos. Radiología. 2017;59(5):368-79. https:// doi.org/10.1016/j.rx.2017.06.003

10. Sarosiek T. Systemic treatment of early breast cancer - current state of knowledge after the conference St Gallen 2017. Pol Merkur Lekarski. 2017;43(257):232-6.

11. Matsen CB, Neumayer LA. Breast Cancer: a review for the general surgery. JAMA Surg. 2013;148(10):971-9. https://doi. org/10.1001/jamasurg.2013.3393

12. Urban LABD, Schaefer MB, Duarte DL, Santos RP, Maranhão NMA, Kefalas AL, etal. Recomendações do Colégio Brasileiro de Radiologia e Diagnóstico por Imagem, da Sociedade Brasileira de Mastologia e da Federação Brasileira das Associações de Ginecologia e Obstetrícia para rastreamento do câncer de mama por métodos de imagem. Radiol Bras. 2012;45(6):334-9. https://doi.org/10.1590/S0100-39842012000600009

13. Miglioretti DL, Zhu W, Kerlikowske K, Sprague BL, Onega T, Buist DSM, et al. Breast Tumor Prognostic Characteristics and Biennial vs Annual Mammography, Age, 549 and Menopausal Status. JAMA Oncol. 2015;1(8):1069-77. https://doi.org/10.1001/ jamaoncol.2015.3084

14. Ribeiro RA, Caleffi M, Polanczyk CA. Custo-efetividade de um programa de rastreamento organizado de câncer de mama no Sul do Brasil. Cad Saúde Pública. 2013;29(Suppl. 1):s131-s145. https://doi.org/10.1590/0102-311X00005213 
15. Coleman C. Early Detection and Screening for Breast Cancer. Semin Oncol Nurs. 2017;33(2):141-55. https://doi.org/10.1016/j. soncn.2017.02.009

16. American Cancer Society. Breast cancer stages [Internet]. American Cancer Society; 2017 [accessed on Nov. 14, 2018]. Available from: https:/www.cancer.org/cancer/breast-cancer/ understanding-a-breast-cancer-diagnosis/stages-of-breastcancer.html

17. McDonald ES, Clark AS, Tchou J, Zhang P, Freedman GM.Clinical diagnosis and management of breast cancer. J Nucl Med. 2016;57(Suppl. 1):9S-16S. https://doi.org/10.2967/ jnumed.115.157834

18. Veronesi U, Galimberti V, Mariani L, Gatti G, Paganelli G, Viale G, et al. Sentinel node biopsy in breast cancer: early results in 953 patients with negative sentinel node biopsy and no axillary dissection. Eur J Cancer. 2005;41(2):231-7. https:// doi.org/10.1016/j.ejca.2004.05.009

19. Warrier S, Tapia G, Goltsman D, Beith J. An update in breast cancer screening and management. Womens Health (Lond). 2016;12(2):229-39. https://doi.org/10.2217/whe.15.105
20. Migowski A, Silva GAE, Dias MBK, Diz MDPE, Sant’Ana DR, Nadanovsky P. Guidelines for early detection of breast cancer in Brazil. II - new national recommendations, main evidence, and controversies. Cad Saúde Pública. 2018;34(6):e00074817. http://dx.doi.org/10.1590/0102-311x00074817

21. Clarke M, Collins R, Darby S, Davies C, Elphinstone P, Evans $\mathrm{V}$, et al. Effects of radiotherapy and of differences in the extent of surgery for early breast cancer on local recurrence and 15- year survival: an overview of the randomised trials. Lancet. 2005;366(9503):2087-106. https://doi.org/10.1016/s01406736(05)67887-7

22. Prat A, Pineda E, Adamo B, Galván P, Fernández A, Gaba L, et al. Clinical implications of the intrinsic molecular subtypes of breast cancer. Breast. 2015;24(Suppl. 2):S26-S35. https://doi. org/10.1016/j.breast.2015.07.008

23. Duffy SW, Vulkan D, Cuckle H, Parmar D, Sheikh S, Smith RA, et al. Effect of mammographic screening from age 40 years on breast cancer mortality (UK Age trial): final results of a randomised, controlled trial.Lancet Oncol. 2020;21(9):1165-72. https://doi.org/10.1016/S1470-2045(20)30398-3 